\title{
Appropriate use of anti-thrombotic therapy in patients with atrial fibrillation at single- center experience, Northwest Ethiopia
}

\author{
Ermiyas Endewunet, Abilo Tadesse ${ }^{*}$, Aynishet Adane and Mohamed Abdulkadir
}

\begin{abstract}
Background: Atrial fibrillation (AF) is the commonest clinically significant ECG-evidenced sustained cardiac arrhythmia in clinical practice. Disability and mortality attributed to AF is high in low-income regions like subSaharan Africa. The risk of stroke/TIA in patients with AF can be significantly reduced with anti-thrombotic therapy. Despite the existing evidence of its benefit, significant percentages of AF patients eligible for anti-thrombotic therapy are undertreated in the region.

Methods: A hospital-based cross-sectional study was conducted to determine the appropriate use of antithrombotic therapy in patients with AF between December 1, 2018 and September 30, 2019 at Cardiac Clinic, University of Gondar hospital, Northwest Ethiopia. Consecutive sampling method was used to recruit 210 study subjects. Patients were interviewed to obtain socio-demographic data. Relevant medical history and laboratory parameters were obtained from patients' records. Diagnosis of atrial fibrillation was based on detection of irregular arterial pulse and presence of 'f' waves on 12-lead ECG tracing. Clinical evaluation, echocardiography, chest X-ray and blood chemistry were used to diagnose underlying causes of AF. Data was entered into EPI Info version 4.4.1 and analyzed using SPSS version 20. Bi-variate and multi-variate logistic regression analyses were used to identify associated factors with appropriate use of anti-thrombotic therapy in patients with atrial fibrillation. $P$-values $<0.05$ were used to declare significant association.

Results: A total of 210 patients were included in the study. The mean age of patients was $51.29 \pm 17.2$ years. Twothirds (145/210) of participants were females. Seventy-four (35\%) had valvular AF, while 136/210 (65\%) had nonvalvular AF. Sixty-six percent (139/210) of study subjects were appropriately treated with anti-thrombotic therapy. Appropriately treated subjects in valvular AF group and non-valvular AF group were 58/74 (78\%) and 81/136 (60\%) respectively. On multi-variate analysis, 'can afford for regular INR monitoring' (AOR $=2.6095 \% \mathrm{Cl}: 1.10-6.10, P=$ 0.001 ) was significantly associated with appropriate use of anti-thrombotic therapy.
\end{abstract}

Conclusion: Sixty-six percent of AF patients eligible for anti-thrombotic therapy were appropriately treated. Intervention program to access 'regular INR monitoring' should be practiced to escalate utilization rate of antithrombotic therapy (warfarin) in eligible AF patients.

Keywords: Atrial fibrillation, Anti-thrombotic therapy, Northwest Ethiopia

\footnotetext{
* Correspondence: abilotad@gmail.com

Department of Internal Medicine, College of Medicine and Health Sciences,

University of Gondar, Gondar, Ethiopia
}

(c) The Author(s). 2020 Open Access This article is licensed under a Creative Commons Attribution 4.0 International License, which permits use, sharing, adaptation, distribution and reproduction in any medium or format, as long as you give appropriate credit to the original author(s) and the source, provide a link to the Creative Commons licence, and indicate if changes were made. The images or other third party material in this article are included in the article's Creative Commons licence, unless indicated otherwise in a credit line to the material. If material is not included in the article's Creative Commons licence and your intended use is not permitted by statutory regulation or exceeds the permitted use, you will need to obtain permission directly from the copyright holder. To view a copy of this licence, visit http://creativecommons.org/licenses/by/4.0/. The Creative Commons Public Domain Dedication waiver (http://creativecommons.org/publicdomain/zero/1.0/) applies to the data made available in this article, unless otherwise stated in a credit line to the data. 


\section{Background}

Atrial fibrillation (AF) is the commonest ECG-evidenced sustained cardiac arrhythmia in clinical practice. Although the burden of AF is greater in developed countries, disability and mortality attributed to AF is maximal in developing countries due to limited health care access [1-6]. Clinical risk factors (older age, hypertension, diabetes and heart disease), echocardiographic features (reduced left ventricular ejection fraction, left atrial enlargement, left atrial spontaneous echo contrast, complex aortic plaque), and cardiac biomarkers (increased serum high-sensitivity Troponins, NTerminal pro-Brain Natriuretic Peptide) are associated with an increased risk of AF. Although rheumatic heart disease is the major cause of AF in sub-Saharan Africa, non-valvular cardiac causes are rising due to epidemiological transition in the region [5-8]. AF is responsible for $15-20 \%$ of all strokes, and causes 5-fold increased risk in ischemic stroke. Adjusted-dose vitamin $\mathrm{K}$ antagonists (warfarin) and antiplatelet agents reduce the incidence of stroke by 65 and $20 \%$ respectively $[3-5,9]$. Guidelines recommend that nonvalvular $\mathrm{AF}$ patients with $\mathrm{CHA}_{2} \mathrm{DS}_{2}$ VASc score $\geq 2$ and valvular AF patients regardless of stroke risk score should be started on antithrombotic therapy unless contraindicated [1-3, 9-12]. Despite the existing evidences and guidelines, several studies have demonstrated suboptimal use of oral anti-thrombotic therapy in clinical practice. Predictors of suboptimal use in eligible AF patients include, but not restricted to, female sex, elderly (age $\geq 75$ years), rural residency, paroxysmal AF type, lower $\mathrm{CHA}_{2} \mathrm{DS}_{2} \mathrm{VASc}$ score, co-existing co-morbidity type, fear of bleeding complication, previous bleeding episodes, limited access to or high cost of INR monitoring, limited opportunity to implement guideline, and health care setting type [3-7, 9, 13-15].

Therefore, this study aimed to determine appropriate use of antithrombotic therapy in patients with AF in routine clinical practice in Northwest Ethiopia.

\section{Methods}

\section{Study settings}

A hospital-based cross sectional study was conducted between December 1, 2018 and September 30, 2019 at Cardiac Clinic, University of Gondar hospital. The hospital is located in Northwest Ethiopia, which is $750 \mathrm{~km}$ away from the capital, Addis Ababa. The hospital has a catchment population of $5 \mathrm{~m}$ people.

\section{Study subjects and variables Study subjects}

Patients with ECG-confirmed atrial fibrillation who had follow up at Cardiac Clinic, University of Gondar hospital, during the study period were considered as study population. Patients intolerant or contraindicated for anti-thrombotic therapy, and treated with anti-thrombotic therapy for other indications were excluded from the study.

\section{Study variables}

Dependent variables: Appropriate use of anti-thrombotic therapy in patients with AF.

Independent variables: 1) Socio demographic characteristics -age, sex, marital status, educational status and place of residence 2) Patient-related factors -eligibility for treatment, medication side effects, contra indication to treatment, and afford for INR monitoring 3) Clinical factors- heart failure, hypertension, diabetes, chronic kidney disease, $\mathrm{CHA}_{2} \mathrm{DS}_{2} \mathrm{VASec}$ score, type of $\mathrm{AF}$, prior stroke/TIA, and hyperthyroidism.

\section{Sample size and sampling procedure}

The sample size was calculated using Fisher's formula at a prevalence of $15 \%$ with a confidence interval of $95 \%$ and degree of precision of $5 \%$. Consecutive sampling method was used to recruit 210 study subjects. No special events were noticed in study subjects or clinical care setting during the study period [16].

\section{Data collection instrument and procedures}

Data were collected through an investigator administered pre-designed questionnaire. Patients were interviewed to obtain socio-demographic data. Focused clinical examination was done to each of study subjects. Relevant medical history and laboratory parameters were obtained from patients' records. Diagnosis of atrial fibrillation was based on detection of irregular arterial pulse and ' $\mathrm{f}$ ' waves on 12-lead ECG tracing. Clinical evaluation, echocardiography, chest X-ray and blood chemistry were used to diagnose underlying causes of AF.

Twelve-Lead ECG (ECG 1200G, YSIP-155, Beijing, China) were performed on all patients by physician with standardization of $1 \mathrm{mV}=10 \mathrm{~mm}$ and paper speed of 25 $\mathrm{mm} / \mathrm{sec}$. ECG-based AF diagnoses were reviewed by a cardiologist.

Two-Dimensional Doppler Transthoracic Echocardiography (B/W Digital Ultrasound Scanner, ARI group, China) was performed for AF patients with heart failure by a cardiologist to determine abnormalities on ventricular ejection fraction, valve morphology, ventricular wall size and motion, and atrial and ventricular chamber dimensions.

Venous blood samples were collected from AF patients in plain tubes and centrifuged at $2500 \mathrm{rpm}$ for $15 \mathrm{~min}$ at room temperature to obtain serum. Serum glucose and creatinine were determined by enzymatic glucose oxidase and kinetic alkaline picrate method respectively using Mindray BS-480 (Shenzhen Mindray Bio-Medical electronics Co., Ltd., China) clinical chemistry analyzer. Thyroid function tests $\left(\mathrm{TSH}, \mathrm{T}_{4}\right.$ and $\mathrm{T}_{3}$ ) were determined in whom thyroid disorders were suspected. Thyroid function tests were determined using Radioimmunoassay (RIA) technique (Roche, Switzerland), and kits were from Beijing Isotope Nuclear Electronic Co., Beijing, China. 


\section{Data analysis}

Data were entered into EPI Info version 4.4.1 and transported to SPSS version 20 for analysis.

Patient characteristics were reported as counts (percentages) for categorical variables, and mean with standard deviation for continuous variables. Both bi-variate and multi-variate logistic regression analyses were used to identify independently associated factors with appropriate use of anti-thrombotic therapy in patients with atrial fibrillation. Those variables with a $P$-value $<0.2$ in the bi-variate analysis were exported to multi-variate analysis to control the possible effect of confounders. Adjusted odds ratio (AOR) with 95\% confidence interval (CI) and P-value < 0.05 were used to select independently associated variables with appropriate use of antithrombotic therapy in patients with atrial fibrillation.

\section{Definition of terms}

Atrial fibrillation: ECG-evidenced cardiac rhythm disorder where the normal atrial ' $\mathrm{P}$ ' waves are replaced by chaotic, fibrillatory ' $\mathrm{f}$ ' waves. It was clinically detected by irregular arterial pulse and confirmed by 12-lead ECG tracing $[1,2]$.

Anti-thrombotic therapy: Medications (anti-platelets and anticoagulants) which are given for patients with AF who are at high-risk of developing systemic embolic events.

Appropriateness to anti-thrombotic therapy: Patients are considered as appropriately treated with anti-thrombotic therapy when they are given oral anticoagulants for $\mathrm{CHA}_{2} \mathrm{DS}_{2}$ VASc score $\geq 2$, aspirin/oral anticoagulants for $\mathrm{CHA}_{2} \mathrm{DS}_{2}$ VASc score of 1 , no treatment for $\mathrm{CHA}_{2} \mathrm{DS}_{2-}$ VASc score of 0 , oral anticoagulants for patients of valvular AF irrespective of the $\mathrm{CHA}_{2} \mathrm{DS}_{2}$ VASc score, and oral anticoagulants for patients of hypertrophic cardiomyopathy with AF independent of the $\mathrm{CHA}_{2} \mathrm{DS}_{2}$ VASc score. Patients with AF are inappropriately treated with anti-thrombotic therapy when they are not treated according to the above recommendation $[1,2]$.

$\mathrm{CHA}_{2} \mathrm{DS}_{2}$ VASc score: Congestive heart failure or left ventricular ejection fraction $<40 \%$ (score 1 ), hypertension (score 1), age $\geq 75$ years (score 2), diabetes (score 1), prior stroke/TIA (score 2), vascular diseases (prior myocardial infarction, peripheral arterial disease or aortic plaque) (score 1), age 65-74 years (score 1), sex category (female, score 1).

Framingham criteria: Clinical criteria for heart failure diagnosis, and require presence of either two major, or one major and two minor criteria. Major criteria include paroxysmal nocturnal dyspnea, neck vein distension, acute pulmonary edema, positive hepatojugular reflex, rales, $\mathrm{S}_{3}$ gallop, increased venous pressure $>16 \mathrm{cmH}_{2} \mathrm{O}$, cardiomegaly, and weight loss $\geq 4 \mathrm{~kg}$ in response to treatment. Minor criteria include nocturnal cough, dyspnea on ordinary exertion, pleural effusion, tachycardia (Pulse rate $\geq 120 \mathrm{bps}$ ), hepatomegaly, extremity edema, and vital capacity reduced by one-third from normal.
HAS-BLED score: Uncontrolled hypertension (score 1), abnormal kidney or liver disease (score 1, each), stroke (score 1), bleeding predisposition or tendency (score 1, each), labile INR (TTR <60\% score 1), elderly (age $\geq 65$ years, score 1), and drugs or alcohol (score1, each). HAS-BLED score is used to assess the risk of bleeding, in which high risk patients (score $\geq 3$ ) should be reviewed and followed frequently [17].

TTR (Time in INR Therapeutic Range): The duration of time in which the patient's international normalized range (INR) values were within a desired range (INR $=2-3$ ).

Valvular-AF: AF in the presence of moderate to severe mitral stenosis, mechanical prosthetic valve, or mitral valve repair.

Non-valvular AF: AF in the absence of moderate to severe mitral stenosis, mechanical prosthetic valve, or mitral valve repair.

Hypertension: Presence of persistently elevated systolic blood pressure $\geq 140 \mathrm{mmhg}$ and/or diastolic blood pressure $\geq 90 \mathrm{mmhg}$ in patients aged 18 years of age and above, history of hypertension, or the use of antihypertensive drug(s).

Diabetes mellitus: Fasting serum glucose $\geq 126 \mathrm{mg} / \mathrm{dl}$, history of diabetes, or use medications for diabetes.

Chronic kidney disease: Abnormalities of kidney structure or function present for more than 3 months, with implications for health. Diagnosis of chronic kidney disease was settled by clinical, biochemical (raised serum creatinine) and/or imaging (ultrasound-proven reduced kidney size) findings.

Heart failure: Clinical syndrome that results from any structural or functional impairment of ventricular filling or ejection of blood. The Framingham criteria were used to diagnose heart failure.

Stroke/TIA: Neurological deficit attributed to an acute focal injury of the central nervous system by a vascular cause. Diagnosis of stroke/TIA was settled by clinical and imaging (brain CT/MRI) evaluation.

Hyperthyroidism: Clinical state that involves excess synthesis and secretion of thyroid hormones by the thyroid gland. Diagnosis of hyperthyroidism was made in the presence of suggestive clinical symptoms and signs including enlarged thyroid gland, and confirmed by RIA test from serum revealing low $\mathrm{TSH}$ and/or raised $\mathrm{T}_{3} / \mathrm{T}_{4}$.

\section{Ethical considerations}

Ethical clearance was obtained from the Institutional Review Board of College of Medicine and Health Sciences, University of Gondar. Formal letter of permission was obtained from University of Gondar hospital administrative body. Study subjects were recruited only after informed written consent was obtained from them. All data obtained were treated confidentially. During the data collection process, those patients who were found 
to have atrial fibrillation were taken care of as per the recommendations of AHA/ACC/HRS guidelines for the management of patients with atrial fibrillation.

\section{Result}

Socio demographic characteristics of study participants A total of 210 patients with AF were included in the study. The male-to-female ratio was 1:2 (65 males and 145 females). The mean age of patients at diagnosis was $51.3 \pm 17.2$ years. Majority of them $(75 \%)$ were aged less than 65 years. Half of them (51\%) were rural residents and (56\%) never joined formal education. Almost all of them were non-smoker (97\%) and casual alcohol consumer $(93 \%)$ (Table 1$)$.

Table 1 Socio-demographic characteristics of patients with atrial fibrillation at Cardiac Clinic, UOG hospital, Northwest Ethiopia, December 1, 2018 to September 30, 2019

\begin{tabular}{|c|c|c|}
\hline Variable & Number (No) & Percent (\%) \\
\hline \multicolumn{3}{|l|}{ Age category } \\
\hline$<65$ years & 158 & 75.2 \\
\hline $65-74$ years & 34 & 16.2 \\
\hline$\geq 75$ years & 18 & 8.6 \\
\hline \multicolumn{3}{|l|}{ Sex } \\
\hline Male & 65 & 31.0 \\
\hline Female & 145 & 69.0 \\
\hline \multicolumn{3}{|l|}{ Residence } \\
\hline Rural & 102 & 48.6 \\
\hline Urban & 108 & 51.4 \\
\hline \multicolumn{3}{|l|}{ Marital status } \\
\hline Married & 149 & 71.0 \\
\hline Unmarried & 61 & 29.0 \\
\hline \multicolumn{3}{|l|}{ Occupation } \\
\hline Government employee & 19 & 9.4 \\
\hline Merchant & 20 & 9.5 \\
\hline Farmer & 92 & 43.7 \\
\hline House wife & 50 & 23.7 \\
\hline Student & 13 & 6.1 \\
\hline Others* & 16 & 7.6 \\
\hline \multicolumn{3}{|l|}{ Level of education } \\
\hline Unable to read and write & 118 & 56.2 \\
\hline Able to read and write & 39 & 18.6 \\
\hline Primary education & 17 & 8.1 \\
\hline Secondary Education & 15 & 7.1 \\
\hline College and above & 21 & 10.0 \\
\hline \multicolumn{3}{|l|}{ Monthly income (Eth. Birr) } \\
\hline$<1500$ & 130 & 61.9 \\
\hline $1500-3000$ & 49 & 23.3 \\
\hline$>3000$ & 31 & 14.8 \\
\hline
\end{tabular}

Note: ${ }^{*}=$ retired or no job

\section{Clinical characteristics of patients}

Seventy-four (35\%) patients had valvular AF, predominated by rheumatic mitral valve disease, while 136/ 210 (65\%) had non-valvular AF (Table 2). Heart failure (91\%) was the commonest identified clinical condition in AF patients, followed by hypertension (22\%), stroke/TIA (19\%), and hyperthyroidism (18\%) (Table 3). Underlying causes of heart failure were valvular heart disease $(52 \%)$, coronary artery disease (16\%), dilated cardiomyopathy (11\%), Cor pulmonale (11\%) and hypertensive heart disease (10\%) (Fig. 1). The $\mathrm{CHA}_{2} \mathrm{DS}_{2}$ VASc scores of patients with nonvalvular AF were calculated and most (96\%) of them scored 2 or above.

\section{Anti-thrombotic therapy}

One hundred-sixty-one $(76 \%)$ patients were on antithrombotic therapy, of which 137 (65\%) were on warfarin (or warfarin with aspirin), and 24 (11\%) were on aspirin. The remaining 49 (24\%) were not in any form of anti-thrombotic therapy (Fig. 2). Sixty-six percent $(139 / 210)$ of study subjects were appropriately treated with anti-thrombotic therapy. Seventy-eight percent $(58 / 74)$ in valvular AF group and 60\% (81/136) in non-valvular AF group were appropriately treated. The rest, 71/210 (34\%) AF patients were inappropriately treated. All of the inappropriately treated cases were undertreated or not treated (Fig. 3). The HASBLED score was calculated for all patients, and scored 2 or below. Time in INR Therapeutic Range (TTR) was determined for patients on warfarin, and declared to have suboptimal control (TTR $=39.4 \%)$.

Table 2 Type of AF among patients with AF at Cardiac Clinic, UOG hospital, Northwest Ethiopia, December 1, 2018 to September 30, 2019

\begin{tabular}{lll}
\hline Type of AF & Number (No) & Percent (\%) \\
\hline Non-valvular AF & 136 & $64.8 \%$ \\
CHA $_{2}$ DS $_{2}$ VASC score & & \\
Female & 1 & 0.7 \\
1 & 4 & 2.9 \\
2 & 70 & 51.5 \\
3 & 28 & 20.6 \\
4 & 23 & 16.9 \\
5 & 10 & 7.4 \\
Valvular AF & 74 & $35.2 \%$ \\
Mitral stenosis (moder-Severe) & 69 & 93.2 \\
Mitral valve repair & 2 & 2.7 \\
Prosthetic valve (Mechanical) & 3 & 4.1 \\
Total & 210 & 100 \\
\hline
\end{tabular}


Table 3 Clinical characteristics of patients with atrial fibrillation at Cardiac Clinic, UOG hospital, Northwest Ethiopia, December 1, 2018 to September 30, 2019

\begin{tabular}{|c|c|c|}
\hline Variables & $\begin{array}{l}\text { Number } \\
\text { (No) }\end{array}$ & $\begin{array}{l}\text { Percent } \\
(\%)\end{array}$ \\
\hline \multicolumn{3}{|l|}{ Smoking } \\
\hline Yes & 7 & 3.3 \\
\hline Never & 203 & 96.7 \\
\hline \multicolumn{3}{|l|}{ Alcohol intake } \\
\hline Never & 88 & 41.9 \\
\hline Occasionally & 108 & 51.4 \\
\hline Usually & 14 & 6.7 \\
\hline \multicolumn{3}{|l|}{ Hypertension } \\
\hline Yes & 47 & 22.4 \\
\hline No & 163 & 77.6 \\
\hline \multicolumn{3}{|l|}{ Heart failure } \\
\hline Yes & 190 & 90.5 \\
\hline No & 20 & 9.5 \\
\hline \multicolumn{3}{|c|}{ Diabetes mellitus } \\
\hline Yes & 6 & 2.9 \\
\hline No & 204 & 97.1 \\
\hline \multicolumn{3}{|l|}{ Stroke/TIA } \\
\hline Yes & 39 & 18.6 \\
\hline No & 171 & 81.4 \\
\hline \multicolumn{3}{|c|}{ Hyperthyroidism } \\
\hline Yes & 38 & 18.1 \\
\hline No & 172 & 81.9 \\
\hline \multicolumn{3}{|c|}{ Chronic kidney disease } \\
\hline Yes & 17 & 8.1 \\
\hline No & 193 & 91.9 \\
\hline
\end{tabular}

Factors associated with appropriate use of antithrombotic therapy

Bi-variate and multi-variate logistic regression analyses were used to identify associated factors for appropriate use of anti-thrombotic therapy in patients with AF. On bi-variate analysis, presence of prior stroke/TIA (COR = 3.46, 95\% CI: 1.37-8.7, $P=0.008)$, valvular AF type $(\mathrm{COR}=3.09,95 \% \mathrm{CI}: 1.58-6.07, P=0.001)$ and 'can afford for regular INR monitoring' $(\mathrm{COR}=8.8295 \% \mathrm{CI}$ : 2.80-27.72, $P<0.001$ ) were significantly associated with appropriate use of anti-thrombotic therapy. When significant variables in bi-variate analysis were regressed for multi-variate analysis, only 'can afford for regular INR monitoring' $(\mathrm{AOR}=2.60$ 95\% CI: $1.10-6.10, \mathrm{P}=0.001)$ was independently associated with appropriate use of guideline directed anti-thrombotic therapy (Table 4).

\section{Discussion}

A total of 210 patients with atrial fibrillation were included in the study. Seventy-four (35\%) had valvular AF, while 136 (65\%) had non-valvular AF. Although rheumatic heart disease remained to be a major risk factor for AF in sub-Saharan Africa, non-valvular cardiac causes are evident escalating health problems. Economic and social changes in sub-Saharan Africa are driving on epidemiologic transition to a double burden of disease in the region [4-7].

Heart failure (91\%) was the commonest identified clinical condition in AF patients, followed by hypertension (22\%), stroke/TIA (19\%), and hyperthyroidism (18\%). Valvular heart disease was detected in half (52\%) of heart failure cases. Almost all Patients with AF presented late with symptomatic structural heart disease. Rheumatic heart disease was documented as the prevalent cause of

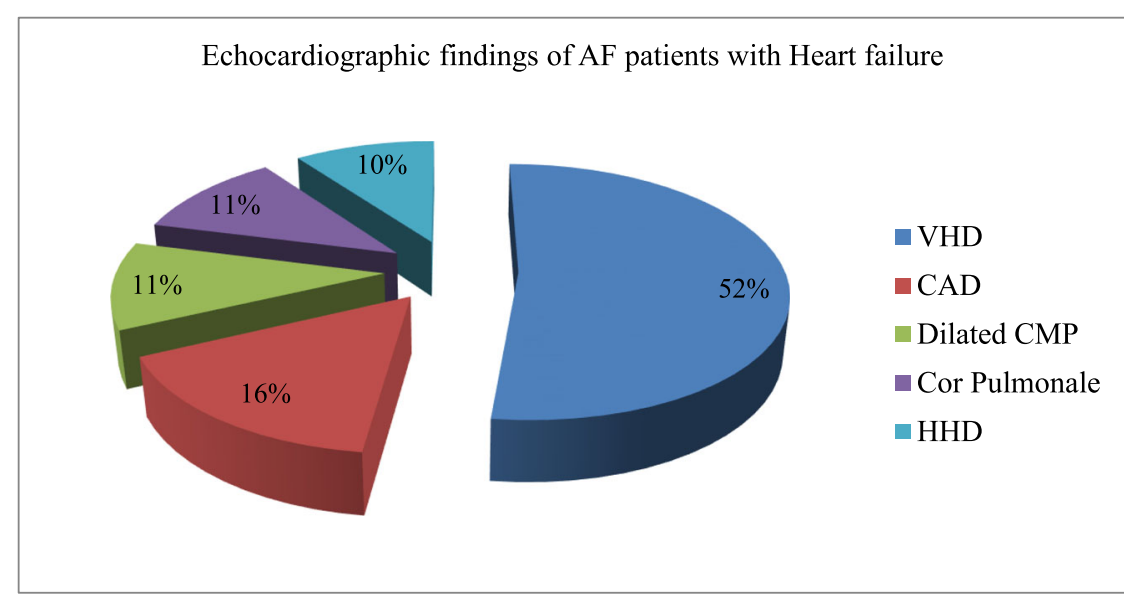

Note: VHD, valvular heart disease; CAD, coronary artery disease; CMP, cardiomyopathy; HHD, hypertensive heart disease

Fig. 1 Echocardiographic findings of 191 AF patients with heart failure at Cardiac Clinic, UOG hospital, December1, 2018 to September 30,2019 


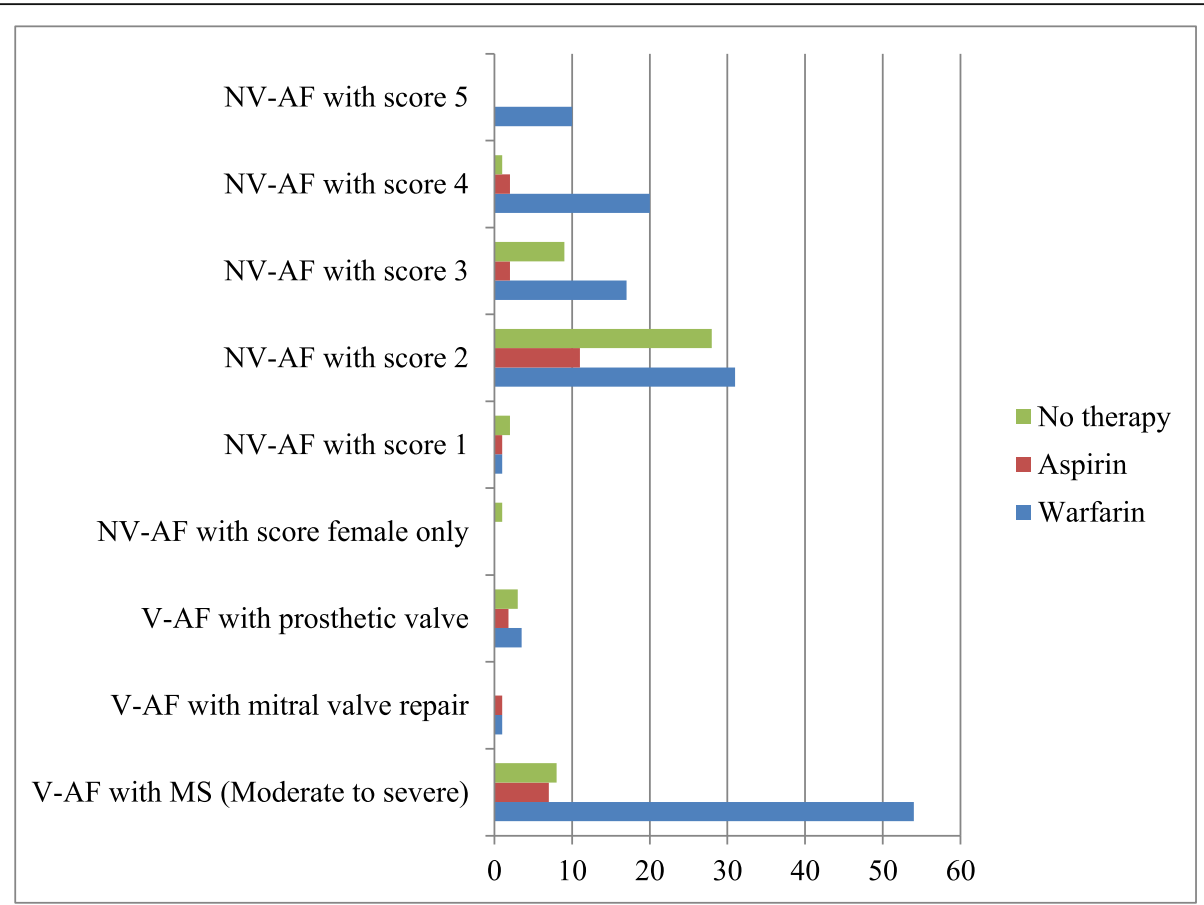

Note: V-AF, valvular atrial fibrillation; NV-AF, Non-valvular atrial fibrillation

Fig. 2 Type of anti-thrombin therapy for valvular AF and non-valvular AF at Cardiac Clinic, UOG hospital, Northwest Ethiopia, December 1, 2018 to September 30, 2019

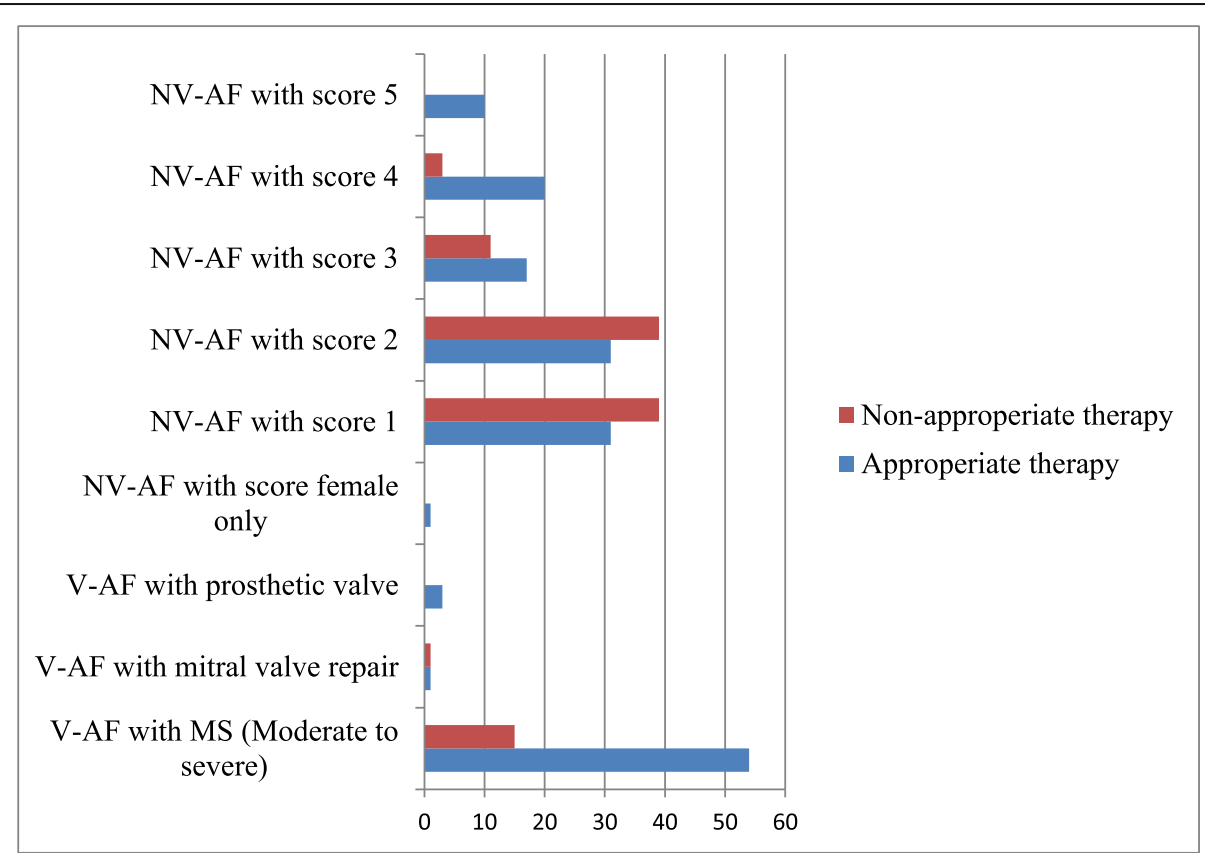

Note: V-AF, Valvular atrial fibrillation; NV-AF, Non-valvular atrial fibrillation

Fig. 3 Appropriateness of anti-thrombotic therapy for AF patients at Cardiac Clinic, UOG hospital, Northwest Ethiopia, December 1, 2018 to September 30, 2019 
Table 4 Bi-variate and multi-variate logistic regression analysis of patients on anti-thrombotic therapy at Cardiac Clinic, UOG hospital, Northwest Ethiopia, December 1, 2018 to September 30, 2019

\begin{tabular}{|c|c|c|c|c|c|}
\hline Variable & Anti-thrombotic therapy Appro. Inappro. & COR (95\%) & P-value & AOR (95\%) & $P$-Value \\
\hline \multicolumn{6}{|l|}{ Stroke } \\
\hline Yes & 336 & $3.46(1.37-8.70)$ & 0.008 & $2.20(0.56-8.70)$ & 0.25 \\
\hline No & 10566 & & & & \\
\hline \multicolumn{6}{|l|}{ Type of AF } \\
\hline Valvular & 5816 & $3.09(1.58-6.07)$ & 0.001 & $1.90(0.80-4.80)$ & 0.14 \\
\hline Non-valvular & 8155 & & & & \\
\hline \multicolumn{6}{|l|}{ INR monitoring } \\
\hline vCan afford & 13556 & $8.82(2.80-27.72)$ & $<0.001$ & $2.60(1.10-6.10)$ & 0.001 \\
\hline Can't afford & 415 & & & & \\
\hline \multicolumn{6}{|l|}{ Heart failure } \\
\hline Yes & 12466 & $0.8(0.46-3.40)$ & 0.67 & & \\
\hline No & 146 & & & & \\
\hline Hypertension & & $0.8(0.73-3.0)$ & & & \\
\hline Yes & 3413 & & 0.28 & & \\
\hline No & 10459 & & & & \\
\hline \multicolumn{6}{|l|}{ Thyrotoxicosis } \\
\hline Yes & 1919 & $0.45(0.22-0.90)$ & 0.026 & $0.80(0.40-1.90)$ & 0.67 \\
\hline No & 11953 & & & & \\
\hline \multicolumn{6}{|l|}{ Age (years) } \\
\hline$\geq 75$ & 153 & $2.80(0.78-10.03)$ & 0.13 & $2.20(0.50-8.70)$ & 0.25 \\
\hline$<75$ & 12369 & & & & \\
\hline \multicolumn{6}{|c|}{ Place of Residence } \\
\hline Urban & 6834 & $1.08(0.50-1.60)$ & 0.77 & & \\
\hline Rural & 7038 & & & & \\
\hline \multicolumn{6}{|c|}{ Formal education } \\
\hline Yes & 10156 & $0.78(0.60-2.50)$ & 0.41 & & \\
\hline No & 3716 & & & & \\
\hline
\end{tabular}

Note: $A F$ atrial fibrillation, $C O R$ crude odds ratio, $A O R$ adjusted odds ratio

valvular heart disease in sub-Saharan Africa [5-8, 18, 19]. Western world studies documented hypertension (30-70\%), coronary artery disease (20-40\%) and diabetes (15-25\%) were common causes of AF; while valvular heart disease (30-60\%), hypertension (30-40\%), dilated cardiomyopathy (5-15\%) and coronary artery disease (5-10\%) were reported AF causes in sub-Saharan Africa $[6-8,11,18]$. This clinical data demonstrated some shared risk factors for AF among developed and developing countries.

Among 210 study subjects, 139 (66\%) subjects were appropriately treated with anti-thrombotic therapy. Appropriately treated subjects in valvular AF group and non-valvular AF group were 58/74 (78\%) and 81/136 (60\%) respectively. Possible explanation for difference in magnitude of appropriately treated subjects among AF groups might be better physicians' experience in managing valvular AF patients, or non-valvular AF patients required arithmetic calculation of $\mathrm{CHA}_{2} \mathrm{DS}_{2} \mathrm{VASc}$ risk score.

Study-based estimated anti-thrombotic utilization rate among eligible AF patients were $70-85 \%$ in Europe, 50$60 \%$ in Asia and 30-60\% in Sub-Saharan Africa. Utilization rate in this study was $66 \%$, higher than a few African study reports. Variable utilization rate in antithrombotic therapy among nations might be related to differences in standard health care and socio-economic conditions [3, 5, 6, 10-14, 19, 20].

This study showed $39.4 \%$ patients on warfarin had good INR control (INR $=2-3$ ), within range of other African study reports. Global reports on therapeutic INR control were $70-80 \%$ in Europe, $40-60 \%$ in Asia, and $30-50 \%$ in Africa $[4,6,8,19]$. Lack of proper titration of anticoagulant dosage was fundamental reason for subtherapeutic INR values. Quality of anticoagulation with 
warfarin is reflected by Time in INR Therapeutic Range (TTR), and patients on warfarin should achieve their TTR $\geq 65 \%$ of the follow-up time. This study revealed calculated HAS-BLED score was 2 or below for all patients. HAS-BLED score is used to assess the risk of bleeding, in which high risk patients (score $\geq 3$ ) required frequent review and follow-ups [21].

In bi-variate analysis, odds of appropriate therapy were provided three fold higher to valvular AF patients (COR $=3.09,95 \%$ CI: $1.58-6.07, P=0.001)$ as compared with non-valvular AF patients. Similarly, patients with prior stroke/TIA were three fold higher $(C O R=3.46$, 95\% CI: $1.37-8.7, P=0.008)$ appropriately treated as compared with those without stroke/TIA. Explanatory reasons could be patients with valvular AF or prior stroke/TIA were 'high risk' patients, in whom antithrombotic therapies were directly indicated.

In multi-variate analysis, patients who 'can afford for regular INR monitoring' were two and half fold higher $(\mathrm{AOR}=2.6095 \% \mathrm{CI}: 1.10-6.10, P=0.001)$ appropriately treated as compared with those who 'can't afford for regular INR monitoring'. This finding was congruent with studies in Africa and Asia in which underutilization of anti-thrombotic therapy were reported among those who had financial constraints $[5-7,14]$. Physicians in the setting prescribe and adjust dosage of warfarin, when AF patients have recent INR determination at hand.

Novel oral anticoagulants (NOACs) are recently introduced anticoagulants, which have a number of advantages over warfarin despite high cost and limited access to antidote (reversal agent). NOACs have more rapid onset and offset than warfarin, are prescribed in fixed doses, have fewer documented food and drug interactions, and do not require routine anticoagulant monitoring. Their use might be considered for eligible non-valvular AF patients who had limited access to INR monitoring $[5,14,20]$.

\section{Limitation of the study}

Identified associated factors might not be causal for appropriate use of antithrombotic therapy in cross-sectional study. Selection bias couldn't be avoided as consecutive sampling method was used to recruit study subjects.

\section{Conclusions}

Non-valvular AF constitutes two-thirds as cause of AF in the setting, prevailing epidemiologic transition to non-communicable diseases. Sixty-six percent of AF patients eligible for anti-thrombotic therapy were appropriately treated. 'Can afford for regular INR monitoring' was independently associated with appropriate use of anti-thrombotic therapy.

\section{Recommendation}

The authors recommend large scale longitudinal study to improve understanding of AF in Ethiopia. Intervention program to access 'regular INR monitoring' should be practiced to escalate utilization rate of anti-thrombotic therapy (warfarin) in eligible AF patients.

\section{Supplementary information}

Supplementary information accompanies this paper at https://doi.org/10. 1186/s12872-020-01659-y.

Additional file 1. Questionnaire.

\section{Abbreviations}

AF: Atrial fibrillation; AHA: American Heart Association; ACC: American college of cardiology; AOR: Adjusted odds ratio; Cl: Confidence interval; $\mathrm{CHA}_{2} \mathrm{DS}_{2}$ VASc score: Congestive heart failure, hypertension, age $\geq 75$, diabetes, stroke or TIA, vascular disease (prior myocardial infarction, peripheral arterial disease or aortic plaque), and sex category (female); ECG: Electrocardiography; ECHO: Echocardiography; HRS: Heart Rhythm Society; HAS-BLED score: Uncontrolled hypertension, abnormal liver and kidney disease, stroke, bleeding predisposition or tendency, labile INR, elderly (age $\geq 65$ years), and drugs or alcohol; INR: International normalized ratio; MI: Myocardial infarction; NOACs: Novel oral anticoagulants; PAD: Peripheral arterial disease; TIA: Transient ischemic attack; TSH: Thyroid stimulating hormone; TTR: Time in INR therapeutic range; VKA: Vitamin $\mathrm{K}$ antagonists

\section{Acknowledgements}

We are grateful to thank the study participants and their health personnel.

\section{Authors' contributions}

EE contributed to the conception, design, data collection, analysis, writing, and review of the manuscript. AT contributed to the conception, design, analysis, writing and review of the manuscript. AA and MA contributed to conception, design, analysis and review of the manuscript. All authors read and approved the final manuscript and approved its submission for publication to BMC Cardiovascular Disorders.

\section{Funding}

Funding for research was obtained from 'Research and Publication Office' of College of Medicine and Health Sciences, University of Gondar. The funding body had no role in the design of the study, data collection, analysis and interpretation of the data.

Availability of data and materials

All data generated and analyzed are included in this research article.

\section{Ethics approval and consent to participate}

Ethical approval was obtained from the Institutional Review Board of College of Medicine and Health Sciences, University of Gondar. Formal letter of permission was obtained from University of Gondar hospital administrative body. Study subjects were recruited only after informed written consent was obtained.

\section{Consent for publication}

NA

\section{Competing interests}

The authors declare that they have no competing interests.

Received: 3 December 2019 Accepted: 6 August 2020

Published online: 17 August 2020

\section{References}

1. January CT, Wann LS, Alpert JS, Calkins H, Cigarroa JE, Conti JB, et al. 2014 AHA/ACC/HRS guideline for the management of patients with atrial fibrillation: executive summary: a report of the American College of 
Cardiology/American Heart Association task force on practice guidelines and the Heart Rhythm Society. J Am Coll Cardiol. 2014;64(21):2246-80.

2. Kirchhof P, Benussi S, Kotecha D, Ahlsson A, Atar D, Casadei B, et al. 2016 ESC guidelines for the management of atrial fibrillation developed in collaboration with EACTS. Eur Heart J. 2016;37(38):2893-962.

3. Li YG, Lip GY. Stroke prevention in atrial fibrillation: state of the art. Internat J Cardio. 2018;287:201-9.

4. Mazurek M, Huisman MV, Rothman K, Paquette M, Teutsch C, Diener HC, et al. Regional differences in antithrobotic treatment for atrial fibrillation: insights from the GLORIA-AF phase II registry. Thromb Haemostat. 2017;117:2376-88.

5. Stambler BS, Ngunga LM. Atrial fibrillation in sub-Saharan Africa: epidemiology, unmet needs, and treatment options. Internat J of Gen Med. 2015;8:231.

6. Nguyen NT, Hilmer SN, Cumming RG. Review of epidemiology and management of atrial fibrillation in developing countries. Internat J of Cardio. 2013;167:2412-20.

7. Ntep-Gweth M, Zimmermann M, Meiltz A, Kingue S, Ndobo P, Urban P, et al. Atrial fibrillation in Africa: clinical characteristics, prognosis, and adherence to guidelines in Cameroon. Europace. 2010;12(4):482-7.

8. Lugero C, Kibirige D, Kayima J, Mondo CK, Freers J. Atrial fibrillation among the black population ina Ugandan teritiary hospital. Int J of Gen Med. 2016; 9:191-8.

9. Pisters R, van Oostenbrugge RJ, Knottnerus IL, De Vos CB, Boreas A, Lodder J, et al. The likelihood of decreasing strokes in atrial fibrillation patients by strict application of guidelines. Europace. 2010;12(6):779-84.

10. Garber JL, Willenborg KL, Rose AE. Analysis of anticoagulant prescribing in non-valvular atrial fibrillation and development of a clinical tool for guiding anticoagulant selection. J Thrombosis Thrombol. 2015;40(2):248-54.

11. Ogawa S, Aonuma K, Tse HF, Huang D, Huang JL, Kalman J, et al. The APHR S's 2013 statement on antithrombotic therapy of patients with nonvalvular atrial fibrillation. J Arrhythmia. 2013;29(3):190-200.

12. Dupree L, De Los SM, Smotherman C. Evaluation of adherence to guidelinedirected antithrombotic therapy for atrial fibrillation at hospital discharge. J Cardiovasc Pharma Therap. 2018;1074248418778804.

13. Pandya EY, Anderson E, Chow C, Wang Y, Bajorek B. Contemporary utilization of antithrombotic therapy for stroke prevention in patients with atrial fibrillation: an audit in an Australian hospital setting. Therap Adv Drug Safety. 2018;9(2):97-111.

14. Lee $\mathrm{I}-\mathrm{H}$, Kim H, Je NK. Underutilization of warfarin for stroke prophylaxis in patients with atrial fibrillation or atrial flutter in Korea. J Cardio. 2015;66(6): 475-81.

15. Gamra H, Murin J, Chiang C-E, Naditch-Brûlé L, Brette S, Steg PG. Use of antithrombotics in atrial fibrillation in Africa, Europe, Asia and South America: insights from the international realise AF survey. Arch Cardiovasc Dis. 2014;107(2):77-87.

16. Wayne WD, Cross CL. Biostatistics: A foundation for analysis in health sciences. 10 ed. New Jersey: Wiley; 2013.

17. Nieuwlaat R, Capucci A, Camm AJ, Olsson SB, Andresen D, Davies DW, et al. Atrial fibrillation management: a prospective survey in ESC member countries: the euro heart survey on atrial fibrillation. Eur Heart J. 2005;26(22): 2422-34.

18. Tegene E, Tadesse I, Markos Y, Gobena T. Prevalence and risk factors for atrial fibrillation and its anticoagulant requirement in adults aged $>40$ in Jimma town, Southwest Ethiopia: a community based cross-sectional study. IJL Heart Vasc. 2019;22:199-204.

19. Yadeta D, Semeredin N, Mekonnen G. Prevalence and predictors of atrial fibrillation and its embolic complications in patients with rheumatic heart disease at Tikur Anbessa specialized hospital, Addis Ababa, Ethiopia. Ethiop J Health Dev. 2019:33(1):11-6.

20. Ebrahim I, Bryer A, Cohen K, Mouton JP, Msemburi W, Blockman M. Poor anticoagulation control in patients taking warfarin at a tertiary and districtlevel prothrombin clinic in Cape Town, South Africa. S Afr Med Jour. 2018; 108(6):490-4.

21. Pisters R, Lane DA, Nieuwlaat R, de Vos CB, Crijns HJGM, Lip GYH. A novel user-friendly score (HAS-BLED) to assess 1-year risk of major bleeding in patients with atrial fibrillation: the euro heart survey. Chest. 2010;138(5): 1093-100.

\section{Publisher's Note}

Springer Nature remains neutral with regard to jurisdictional claims in published maps and institutional affiliations.

\section{Ready to submit your research? Choose BMC and benefit from}

- fast, convenient online submission

- thorough peer review by experienced researchers in your field

- rapid publication on acceptance

- support for research data, including large and complex data types

- gold Open Access which fosters wider collaboration and increased citations

- maximum visibility for your research: over $100 \mathrm{M}$ website views per year

At BMC, research is always in progress.

Learn more biomedcentral.com/submissions 